\title{
On the relation between argumentative style and linguistic style
}

\author{
Integrating linguistic-stylistic analysis \\ systematically into the analysis \\ of argumentative style
}

\author{
Ton van Haaften and Maarten van Leeuwen \\ Leiden University Centre for Linguistics (LUCL)
}

\begin{abstract}
Argumentative style is assumed to be instrumental to the implementation of an arguer's strategic plan to resolve a difference of opinion in his/her favor. One important constitutive element of argumentative style are linguistic choices. It is therefore crucial to pay close and systematic attention to linguistic choices and their argumentative functions in the analysis of argumentative style.

In this paper we discuss how a linguistic-stylistic analysis can be conducted systematically by making use of methodological insights from the socalled "linguistic-stylistic approach", and how such an analysis can be integrated with a pragma-dialectical analysis of argumentative discourse. Our aim is to show how such an integration could be helpful in analysing the presentational aspect of an argumentative style, and how the outcomes of such an analysis could be linked to another aspect of argumentative style, namely the strategic considerations implemented in the argumentative discourse and more particularly the argumentative strategies involved.
\end{abstract}

Keywords: argumentative activity type, argumentative strategy, argumentative style, linguistic style, linguistic-stylistic analysis

\section{Introduction}

In the theoretical perspective on argumentative style offered by Van Eemeren (2019; this issue), argumentative styles are seen as ways of implementing the arguers "strategic scenarios", i.e. their "strategic plans" for trying to resolve a difference of opinion in their favour. Compared to the way "style" is conceived in 
linguistics, the notion of argumentative style is on the one hand more specific since its focus is particularly on choices aimed at resolving a difference of opinion by means of argumentation - and on the other hand broader - because in using argumentative discourse to resolve a difference of opinion also other choices than presentational ones are involved (van Eemeren 2019, p.164). As such, "argumentative style" is a more encompassing concept than "linguistic style".

For conducting an argumentative-stylistic analysis, this means that a linguistic-stylistic analysis (i.e. an analysis of the linguistic choices made in the argumentative discourse that is being analysed) should be connected to an analysis of other aspects of argumentative style. It also implies that the linguisticstylistic analysis should be functional for such a more encompassing argumentative stylistic analysis. In other words, a linguistic-stylistic analysis should systematically show how specific linguistic choices are functional or dysfunctional for resolving a difference of opinion and how the specific linguistic choices can be systematically linked to other dimensions of argumentative style, i.e. the argumentative moves that are made, the dialectical route that is chosen and the implementation of strategic considerations (van Eemeren, 2019; this issue). ${ }^{1}$

A linguistic-stylistic analysis of argumentative discourse is also functional for a more encompassing argumentative-stylistic analysis in another sense. Although all dimensions of an argumentative style are equally relevant in shaping it, the analysis of its linguistic presentation is an important means to retrieve the other dimensions also. After all, linguistic presentational devices are also the manifestations of the other dimensions in argumentative discourse (cf. Fahnestock \& Tonnard 2011, p.104).

In our opinion it is of crucial importance to pay close and systematic attention to linguistic choices and their argumentative functions in the analysis of argumentative style. However, the identification and the analyses of linguistic choices in argumentative discourse are often ad hoc: in most cases, a systematic analysis thereof is lacking (cf. Fahnestock 2009; van Leeuwen 2014). In addition, pragmadialectics does not offer the tools yet for such a systematic analysis of this component of argumentative style.

In this paper, we discuss and illustrate how a linguistic-stylistic analysis can be conducted systematically by making use of methodological insights from the so-called "linguistic-stylistic approach" (van Leeuwen 2015; Stukker \& Verhagen

1. The fact that linguistic-stylistic analysis of argumentative discourse as part of a more encompassing argumentative-stylistic analysis is not a linguistic-stylistic analysis for its own sake, does of course not exclude the possibility to do linguistic-stylistic analyses of argumentative discourse for other reasons or from other perspectives, but then these analyses do not contribute to the identification or analysis of the argumentative style of the discourse at stake. 
2019), and how such an analysis can be integrated in a pragma-dialectical analysis of argumentative discourse (see also van Haaften \& van Leeuwen 2018; van Haaften 2019). Our aim is to show how such an integration can be helpful in analysing the presentational aspect of an argumentative style, and how the outcomes of such an analysis can be linked to another aspect of argumentative style, namely the strategic considerations implemented in the argumentative discourse and more particularly the argumentative strategies involved. To this end, we will first discuss the notion of "argumentative strategy" as developed by van Eemeren (2010, 2018) and its relation with linguistic presentational choices (Section 2). Next, we will enunciate the linguistic-stylistic approach and how it can be integrated in a pragma-dialectical analysis of argumentative discourse (Section 3). In Section 4, we will illustrate by means of a case study what an integration of insights from linguistic-stylistics and pragma-dialectics can yield for the study of argumentative style. In the conclusion (Section 5), we wrap up our view on the relation between argumentative-stylistic analysis and linguistic-stylistic analysis.

\section{Argumentative strategies and linguistic choices}

As was stated at the beginning of the Introduction, argumentative styles are assumed to be ways of implementing an arguer's "strategic scenario" or "strategic plan". In order to reveal the "strategic design" of an argumentative discourse, the notions of "strategic manoeuvring" and "argumentative strategy" are crucial (van Eemeren, this issue). When manoeuvring strategically, speakers or writers make an effort to present their discussion moves in a specific way in all stages of the critical discussion. Van Eemeren (2018, pp.116-120; 2019, pp.161-163) makes clear that although strategic manoeuvring taking place in an argumentative discourse may result in the occurrence of several manoeuvres that are strategically unrelated to each other, in argumentative reality the strategic manoeuvring may well be carried out according to a largely deliberate strategic design, where the various strategic manoeuvres are combined in such a way that they are likely to reinforce one another. If this happens more or less consistently in the discourse, the series of individual strategic moves involved constitutes an "argumentative strategy": a coordinated and coherent effort to achieve dialectically as well as rhetorically the result aimed for in the argumentative discourse. ${ }^{2}$

2. Argumentative strategies are highly diverse in nature and are often also highly contextdependent; in addition they can either be used consistently through all phases of a discussion or in only one, or somewhere between these two. A further distinction can be made between argumentative strategies that are aimed at persuading the actual opponent in a discussion and 
Employing an argumentative strategy involves both coordinating the consecutive strategic manoeuvres that are made and coordinating the choices made in each argumentative manoeuvre as regards to the three aspects of strategic manoeuvring (i.e. selection from the "topical potential", adapting to the "audience demand" and exploiting the available "presentational devices"). In this article, we concentrate on the first type of coordination with respect to argumentative strategies, by focusing on the systematic identification and analysis of an important subset of "presentational devices", namely the linguistic choices made by arguers (cf. van Eemeren 2010, pp.118-119), since the analysis of the linguistic choices in actual argumentative discourse is often an important starting point for the identification and analysis of argumentative strategies.

Since van Eemeren \& Houtlosser introduced the concept of strategic manoeuvring (e.g. van Eemeren \& Houtlosser 1999), within this framework very interesting work has been carried out on the linguistic choices arguers make for formulating a discussion move in a reasonable but also effective way (see van Haaften 2019, pp.307-308 for an overview). Much of this literature is concerned with the question of how the semantic and pragmatic properties of linguistic units (morphemes, words, phrases, constructions, sentences, etc) and categories of these, make them particularly appropriate in specific argumentative contexts. An important and not unexpected conclusion that can be drawn from this kind of research is that there is an absence of one-to-one correspondence between a specific linguistic device and a specific strategic argumentative effect. A specific linguistic device can (always in combination with a matching realisation of the two other aspects of strategic manoeuvring) be used to achieve different strategic argumentative effects; and vice versa, a specific strategic argumentative effect can be achieved by choosing different linguistic devices. In the analysis of a specific speech event the relation between a specific linguistic choice in designing an argumentative move and the strategic use of that argumentative move can only be established in relation to the two other aspects of strategic manoeuvring while taking the institutional, situational and textual context in which this argumentative move is made into account.

As said above, if an analysis of linguistic choices in argumentative discourse is to be an adequate method for identifying and analysing argumentative strategies, it will have to be conducted systematically, and not on an ad hoc basis. It is therefore necessary to apply a systematic method of linguistic-stylistic analysis as part of the analysis of strategic manoeuvring and of the analysis of argumen-

those that are intended to be effective in persuading a third party that is in fact the speaker's or writer's primary audience, as in the case of an election debate between politicians, for example. See for details van Eemeren (2010, 2018, 2019; this issue). 
tative style. More specifically, we would like to argue that one should choose the so-called "linguistic-stylistic approach" (van Leeuwen 2015; Stukker \& Verhagen 2019; see also van Haaften \& van Leeuwen 2018; van Haaften 2019) in order to analyse systematically how arguers employ a set of coordinated and coherent linguistic choices in the verbal realisation of their argumentative strategies. We will enunciate this linguistic-stylistic approach and how it can be integrated in a pragma-dialectical analysis of argumentative discourse (Section 3) and show on the basis of a case study what this analysis method can yield for the identification and analysis of argumentative strategies as part of an arguer's argumentative style (Section 4).

\section{The linguistic-stylistic approach and its integration with pragma- dialectics}

The basic assumption of the linguistic-stylistic approach is that language users almost always have a choice when describing a phenomenon or a state of affairs; alternative formulations for describing a phenomenon or state of affairs are considered to be (linguistic) stylistic variants. Furthermore, it is assumed that linguistic-stylistic variants are not interchangeable semantically. Hence, cases that are linguistic-stylistically "neutral" simply do not exist. This assumption is adopted from the framework of "Cognitive Linguistics" and more specifically from the work of Ronald W. Langacker. ${ }^{3}$ Langacker (e.g. 1990) argues convincingly that the semantics of a grammatical form (a sentence, a phrase, a construction, a word etc.) consists of two equally important components: (a) the object to which the grammatical form refers and (b) the way that object is conceptualised by the speaker, the way the speaker wants the hearer to see the object, her/his "construal" of the object:

A speaker who accurately observes the spatial distribution of certain stars can describe them in many distinct fashions: as a constellation, as a cluster of stars, as specks of light in the sky, etc. Such expressions are semantically distinct; they reflect the speaker's alternate construals of the scene, each compatible with its objectively given properties (Langacker 1990, p.61).

According to this assumption, different grammatical forms are related to distinct construals, and thus to distinct meanings, even if they encode the same propositional content. Within the linguistic-stylistic approach, linguistic-stylistic variants

3. This observation is (independently from Langacker's work) also made by Van Eemeren (2010, p.119) with respect to argumentative discourse. 
are considered to be grammatical forms with the same propositional content but with different construals (cf. Stukker \& Verhagen 2019). This holds for conspicuous stylistic variants (e.g. "inheritance tax" and "death tax") but also for less conspicuous or non-conspicuous ones (e.g. "husband" and "spouse"). In this sense, each linguistic-stylistic choice can serve the purpose of framing the argumentative move that is formulated in such a way as to introduce a particular perspective.

The linguistic-stylistic method is further characterised by three methodological principles: (1) using a checklist of linguistic categories, (2) working comparatively and (3) establishing specific communicative or interactional effects on the basis of a semantic and pragmatic analysis of language forms used in the discourse (cf. Leech \& Short 2007; van Leeuwen 2015; van Haaften \& van Leeuwen 2018; Stukker \& Verhagen 2019; van Haaften 2019).

The use of a checklist as a methodical instrument for linguistic-stylistic analysis has been suggested at various times in linguistic and rhetorical approaches to linguistic style, and a variety of such checklists can be found in the literature (cf. van Leeuwen 2015, pp.26-28 and Stukker \& Verhagen 2019, pp.59-87 for an overview). Although the composition of the checklists varies, the idea behind the use of it is the same: a checklist helps the analyst tracing linguistic-stylistic choices that are relevant for the analysis (cf. Leech \& Short 2007, p. 61). As such, the added value of a checklist lies in its heuristic function: running systematically through all the categories mentioned in a checklist, "forces" the analyst to include a wide variation of linguistic devices in his/her analysis - including the less or non-conspicuous ones. Therefore, a checklist is an important tool to identify linguistic-stylistic devices (cf. van Leeuwen 2014, pp.237-238). The checklist formulated by Leech and Short (2007), for instance, which can be found in the Appendix, lists under four main headings many linguistic features - including for instance grammatical features that might otherwise easily be overlooked. The list makes explicit that linguistic-stylistic features occur at all "levels" of a text. ${ }^{4}$

Although the use of a checklist is an important tool for analysing linguisticstylistic features in a systematic way, it is not a panacea. Working systematically through the checklist reduces the risk of overlooking pertinent linguistic devices but it cannot remove this risk completely (cf. van Leeuwen 2014, p.238). For one thing, the checklist is not exhaustive: a complete list would result in an instru-

4. Leech \& Short (2007) developed their method, including the checklist, for the analysis of English fictional prose. However, their method is applicable also to non-fictional discourse genres. In general, the linguistic-stylistic approach assumes that linguistic style is a universal communicative phenomenon and that the method for linguistic style analysis with a linguistic foundation can be applied in all communicative domains because it is based on the semantic construal component of linguistic forms in a specific discourse in a specific language (cf. Stukker \& Verhagen 2019). 
ment whose length would make it unmanageable in analytical practice. Furthermore, when identifying linguistic-stylistic features in discourse the analyst needs to be on the lookout not only for the presence of linguistic devices but also for their absence. Thus, linguistic style is not just a matter of using certain linguistic devices but, equally, of avoiding a particular kind of phrasing. And even when a checklist is used, identifying linguistic devices remains a partly intuitive process based on the knowledge of one or more analysts. If several analysts are involved in the linguistic-stylistic analysis of the same argumentative discourse, then the analysis is naturally also more intersubjective. ${ }^{5}$

It is therefore important to not only use a checklist for identifying linguistic devices but also to proceed by comparison. The possibly relevant presence or absence of linguistic devices in a certain piece of argumentative discourse is more easily brought to light if the analyst compares it to another relevant piece of argumentative discourse that is expressed in the same discussion context, for example, or which the analyst has created specially as a comparative criterion in the analysis. This manner of working reduces the risk of the analyst overlooking pertinent linguistic devices, as does systematically running through a checklist. The result of using a checklist and working comparatively is a list of numerous linguistic phenomena that can be relevant for the linguistic-stylistic analysis of a particular argumentative discourse.

The core of the linguistic-stylistic method is the semantic and pragmatic analysis of language forms identified in the discourse with a view to establishing the specific communicative or interactional effects (cf. Leech \& Short 2007 and Verhagen \& Stukker 2019). This obviously presupposes a certain amount of linguistic background knowledge: behind every category mentioned in the checklist we find a whole "world" of linguistics. The categories mentioned in the checklist are often not directly applicable in the analysis of the discourse; they need to be "translated". For example, the analyst needs to translate an abstract category like "suffixes" into a concrete linguistic-stylistic phenomenon in the argumentative discourse, such as "plural", and then needs to analyse the communicative effect(s) of plurals in the specific argumentative discourse on the basis of their semantics and pragmatics.

In order to integrate a systematic linguistic-stylistic analysis into a general pragma-dialectical analysis of argumentative discourse, the following methodological steps are necessary (cf. van Haaften \& van Leeuwen 2018; van Haaften 2019):

5. See van Leeuwen (2015, pp.36-39 and Chapter 3) and Stukker \& Verhagen (2019, pp.59-87) for a more detailed discussion of the methodology of using a checklist in linguistic-stylistic analysis of fictional and non-fictional discourse. 
1. The argumentative discourse has to be reconstructed in an analytic overview of the empirical counterparts of the four discussion stages: the initial situation, the starting points, the argumentative means and criticisms and the outcome of the actual argumentative discourse. As part of this reconstruction, the specific dialectical and rhetorical aims of each stage in the speech event(s) have to be determined, taking into account the restrictions and opportunities imposed by the activity type in which the discourse takes place (cf. van Eemeren 2010, 2018 and van Eemeren \& Snoeck Henkemans 2016).

2. For each empirical counterpart of a discussion stage, strategic linguistic choices must be identified systematically by using the methodological tools from the linguistic-stylistic approach discussed above, i.e. specific linguistic devices are charted "bottom-up" on the basis of the checklist and by working comparatively. This analysis will result in a list of linguistic choices for the argumentative discourse that are assumed to be used in some form or another to manoeuvre strategically.

3. The obtained list of initial linguistic findings must be further reduced in a top-down analysis, given that our interest in conducting the analysis lies in the question of what linguistic devices are used strategically for the reconstructed goals envisaged by a speaker or writer. We must therefore, for each of the linguistic devices identified in the bottom-up analysis, determine the (presumed) strategic argumentative effect(s) on the basis of semantic and pragmatic analysis of the language forms, and subsequently establish or plausibly justify, whether they contribute to achieving the reconstructed dialectical and rhetorical goals and precisely how they do this. In other words, during the top-down analysis, the initial list of linguistic-stylistic observations (i.e. the result of Step 2) must be reduced in the light of the outcomes of the argumentative reconstruction carried out in Step $1 .^{6}$

4. Finally, we must investigate whether argumentative strategies can be found within one or more empirical counterparts of the discussion stages or within the discussion as a whole. In other words, we must check for the presence of a set of coordinated and coherent linguistic choices in designing individual strategic manoeuvres to influence the result of a particular stage of the resolution process, or the discussion as a whole. In order to do this, we must investigate whether various (systematic) linguistic choices sort out similar effects, i.e. whether clusters of linguistic choices contribute to a certain "construal" of the argumentative discourse in a particular stage of the resolution process, or

6. See van Leeuwen (2015) and Stukker \& Verhagen (2019) for a more elaborate discussion and illustration of combining bottom-up and topdown-analysis in general within the linguisticstylistic approach. 
the discussion as a whole. To achieve this, after the analyst has analysed the individual strategic manoeuvres, their presentational design and the strategic effect of their presentational design (step 3), an analysis should be made of whether and in what way individual strategic manoeuvres contribute to one or more argumentative strategies. ${ }^{7}$

\section{An illustration: The Yuri case}

\subsection{The case}

The case study that we will use to illustrate what the systematic linguistic-stylistic analysis can yield for the identification and analysis of argumentative strategies as part of an arguer's argumentative style consists of the oral pleadings by the lawyers and the order of the judge that were delivered in the so-called "Yuri case", in which the Dutch gymnast Yuri van Gelder played a leading role. During the Olympics in Rio de Janeiro in 2016, Yuri van Gelder qualified for the finals of the rings competition, after a decade full of ups and downs in which he for example became world champion in 2005 but was also several times suspended and withdrawn from the team because of the use of cocaine. During the Olympics in 2016, he could finally compete at the highest level, and qualified for the finals. In order to celebrate this qualification, Van Gelder went to the "Holland Heineken House", the meeting place for the Dutch during the Olympic Games. Van Gelder, who had to train the next morning with the Dutch gymnast team, had been warned not to drink any alcohol, and he had promised his coach via WhatsApp to be back in his hotel around midnight. However, after visiting the Holland Heineken House, where he drunk several beers, he left the Olympic village - which was not allowed for safety reasons. After going out he returned to his hotel in the early morning;

7. The four steps described here, articulate - for reasons of analytical transparency - the way one is to proceed if the linguistic presentational devices used in the argumentative discourse are the only or the main clues for identifying and analysing an argumentative strategy. However, it has to be stressed that evidence about which argumentative strategy is used can, and regularly will, also be provided by the choices the arguer makes with respect to the two other aspects of strategic manoeuvring, i.e. topical choice and audience demand. In the latter case the choices of the linguistic presentational devices can be used to verify (and prove to support or subvert) the evidence provided by the choices with respect to the two other aspects of strategic manoeuvring. In an optimal argumentative strategy, the three aspects of strategic manoeuvring are attuned to each other. Part of an analysis of an argumentative strategy, should therefore be to determine the way in which the attunement of the three aspects of strategic manoeuvring is realised (cf. van Eemeren 2018, pp.116-120). 
according to his teammates he caused commotion and was drunk. He went to bed and woke up around 3 PM, which meant that he had missed the training with his team. The Dutch Olympic Committee suspended Van Gelder because of his behaviour, and sent him home for violating the team's code of conduct. Back in the Netherlands, Van Gelder - the plaintiff - took the Dutch Olympic Committee - the defendant - to court in a so called "civil summary judgement procedure", and demanded to get reinstated in the Olympic team, denying that he had broken the team rules. ${ }^{8}$ Van Gelder's attempt was not successful: his claim was rejected by the judge.

In our demonstration of the linguistic-stylistic approach, we will, for reasons of space, limit ourselves in this article to a systematic linguistic-stylistic analysis of the starting points (the empirical counterpart of the opening stage) in the oral pleadings by the lawyers and in the order of the judge. In other words, we will report on the outcomes of a systematic linguistic-stylistic analysis of those parts in the oral pleadings of the plaintiff and the defendant and in the order of the judge in which the starting points for the discussion are at stake.

\subsection{Identifying argumentative strategies}

What dialectical and rhetorical goals did the defendant, plaintiff and judge strive for respectively in the empirical part of the opening stage of the court case? And what argumentative strategies might have been instrumental for achieving these goals? In order to answer these questions, it is helpful to look at the institutional preconditions of the communicative activity type "civil summary judgement" This activity type belongs to the genre of adjudication in the domain of legal communication. Adjudication aims for the settlement of a dispute by an authorized third party rather than by the parties themselves (Van Eemeren 2010:147). In the case of a civil summary judgement procedure two parties take a difference of opinion to a public civil court, where a judge makes a reasoned decision in favour of one of the parties. The goal of the defendant and plaintiff is to convince the judge of their view on the dispute; the judge aims to terminate the dispute by making a decision that is based on an understanding of the relevant facts and concessions and on the application of relevant legal rules. Like other civil law procedures in the Netherlands, the summary judgement procedure aims for the termination of a well-defined dispute by a judge. The decision is sustained by argumentation that is based on an understanding of the relevant facts and concessions, formulated in terms of conditions for the application of a legal rule, a quasi-legal rule or

8. During the trial Van Gelder's case was defended by his lawyer, Cor Hellingman; the Dutch Olympic Committee was represented by its lawyer, Haro Knijff. 
a contract. Unlike other civil law case procedures, the summary judgement procedure is a very fast procedure meant to deal with urgent cases and there are very few formal procedural legal rules involved.

The institutional preconditions of this activity type do not only indicate the general dialectical and rhetorical goals of the discussants, but also in a general sense the argumentative strategies that the plaintiff, the defendant and the judge are likely to follow given their respective roles in this activity type. For the empirical counterpart of the opening stage of the discussion in the Yuri case, this means that all parties have the dialectical goal of bringing about an establishment of the points of departure that fits within the boundaries of legal reasonableness, and the rhetorical goal of bringing about an establishment of the points of departure that is as effective as possible, each from their own perspective, within these boundaries. This implies an effective choice of procedural and material starting points, an effective adjustment of the chosen procedural and material starting points to the audience and an effective presentational design of the chosen procedural and material starting points, within the boundaries of legal reasonableness (cf. van Eemeren 2010, 2018).

In order to convince the judge, the plaintiff and the defendant each should strategically present their own case as favorably as possible, and the opponents' case as negatively as possible, without becoming legally unreasonable. For the judge it is essential that he makes strategically clear that he is an independent and neutral reviewer of the case and that his verdict is based on the understanding of the relevant facts, and follows from the application of a applicable legal rule, a quasi-legal rule of a contract in this specific context and not from his own personal appreciation. How these general argumentative strategies for plaintiff, defendant and judge have to be worked out in specific cases depends of course on the characteristics of these cases.

Given the events that lead to the civil summary judgment in the Yuri-case (see Section 4.1), two questions are central to both the plaintiff and the defendant:

a. Was Yuri an Gelder reliable and responsible?

b. Was Yuri van Gelder a victim or an offender?

It may be assumed that Yuri van Gelder's lawyer is keen on showing that Yuri was reliable and responsible and that he was a victim; the lawyer of the Dutch Olympic Committee is keen on showing that Yuri is not reliable or responsible and that he is an offender. Thus, given the preconditions of the activity type and the characteristics of the specific case, we may hypothesize that Yuri van Gelder's lawyer will choose the argumentative strategies of downplaying the seriousness of Van Gelder's behaviour and portraying him as a victim as much as possible within the boundaries of legal reasonableness, while the lawyer of the Dutch Olympic 
Committee will choose the opposite argumentative strategies of blowing up the seriousness of Van Gelder's behaviour, and portraying him as an offender as much as possible within the boundaries of legal reasonableness. We further may conjecture that the judge will choose an argumentative strategy of being as neutral as possible with respect to Van Gelder's behaviour within the boundaries of legal reasonableness, restricting himself to facts that can be verified or objectified and are relevant for a judgement from the perspective of the application of an applicable legal rule, a quasi-legal rule or a contract in this specific context.

\subsection{Linguistic-stylistic analysis}

The question now is how we can attest whether the plaintiff, the defendant and the judge really employ these strategies, that is to say carry out a largely deliberate strategic design, where the various strategic manoeuvres are combined in such a way that they are likely to reinforce one another? As we argued earlier we would suggest that here a systematic linguistic-stylistic analysis can help. In order to do this, we followed steps 2-4 of the method described at the end of Section $3 .^{9}$

In the first phase of the linguistic-stylistic analysis - the bottom-up analysis specific stylistic devices were charted on the basis of a Dutch version of the checklist by Leech \& Short (2007), in mutual comparison. ${ }^{10}$ The result of this analysis was a list of stylistic choices for each of the pleadings and the order that are assumed to have been used to manoeuvre strategically. In the second phase of the linguistic-stylistic analysis (i.e. step 3 of the method described at the end of Section 3), the obtained list of initial linguistic findings was further reduced in a top-down analysis, given that our interest in conducting the analysis lies in the question of what stylistic devices are used strategically for the reconstructed goals envisaged by the plaintiff, the defendant and the judge in this case. We therefore established for each of the stylistic devices identified in the bottom-up analysis whether they contribute to achieving the reconstructed argumentative goals and precisely how they do this, by determining the argumentative effect(s) presumably aimed for on the basis of semantic and pragmatic analysis of the language forms.

Finally, we investigated whether the hypothesized argumentative strategies of the plaintiff, the defendant and the judge can be attested. In other words, we checked for the presence of a set coordinated and coherent linguistic choices in designing a set of coordinated and coherent individual strategic manoeuvres to influence the establishment of the starting points of the resolution process.

9. Parts of the relevant outcomes of step 1 of this method were described in Section 4.2.

10. See Van Leeuwen (2015, pp.29-32) for the Dutch version of the checklist that was actually used. 
In the following Section, we will report on the outcomes of our linguisticstylistic analysis. As we will show, a series of linguistic choices can be linked to the hypothesized argumentative strategies that both parties and the judge pursue in the empirical counterpart of the opening stage, namely that the plaintiff will try to downplay the seriousness of Van Gelder's actions and will depict him as a victim as much as possible within the boundaries of legal reasonableness, that the defendant will try to blow up the seriousness of Van Gelder's behaviour and will depict him as an offender as much as possible within the boundaries of legal reasonableness, while the judge will try to be as neutral as possible with respect to Van Gelder's behaviour within the boundaries of legal reasonableness, restricting himself to facts that can be verified or objectified and are relevant in the light of the applicable legal rules in this case. While discussing the various linguistic-stylistic choices, we will refer between brackets to the category of the checklist in the Appendix that is involved.

\subsection{Results of the linguistic-stylistic analysis}

Which linguistic choices did the plaintiff make in formulating his proposals for starting points for the discussion in order to downplay the seriousness of Van Gelder's actions as much as possible within de boundaries of legal reasonableness? ${ }^{11}$ One of the points of interests mentioned under category $A_{1}$ in the checklist is the use of words with particular suffixes. It is striking that the plaintiff characterizes Van Gelders' night out in Dutch as an "avondje" (literally: "small evening") twice. By using the Dutch diminutive suffix "-je", the proportion of the incident is depicted as relatively unimportant. A further look at the plaintiff's pleading reveals other instances of euphemistic lexical choices as well (A1): for instance, Van Gelder's apparent alcohol abuse is characterized neutrally as "consumption of alcohol" and "relaxation". In addition, the plaintiff does not state that Van Gelder missed the training next morning because he was "sleeping off his hangover", but because he was "sleeping" and because he was "recovering sleep" - which are both more neutral. Further, the plaintiff does not state that Van Gelder's behaviour caused "anger" in the gymnastics team, but "perhaps annoyance". In other words, the plaintiff uses a noun that functions euphemistically, combined with an adverb

11. For reasons of space, it is not possible to elaborate on the question what precisely "legal reasonableness" entails in the Yuri case. But it can be assumed that the strategic manoeuvring by the plaintiff, the defendant and the judge participating in this civil summary judgement procedure, is in all three cases bound by a selection of legal principles, norms, conventions and procedures of Dutch Civil Law, partly codified in the Dutch Civil Code and the Dutch Code of Civil Procedure. In the analysis that we present in this section, it is presumed that the plaintiff, the defendant and the judge in the Yuri case do not transgress these boundaries and we aim to show how they try to be as effective as possible within them. 
that serves a hedging function (A5) and that suggests even more that the inconvenience caused by Van Gelder's behaviour was not very big. The plaintiff also implies this by using rhetorical questions $\left(\mathrm{B}_{1} / \mathrm{C}\right)$ : "Did the other athletes look pale, then? Was Epke (i.e. Epke Zonderland, one of Van Gelder's team members) not able anymore to perform gymnastics?" From the context it is evident that the implied answer to both questions is "no" - steering again towards the conclusion that Van Gelder's behaviour did not really affect his teammates negatively. Finally, the plaintiff's statement that Van Gelder "slipped inside" when he came back from his night out is relevant. The verb ( $\left.\mathrm{A}_{4} / \mathrm{A}_{1}\right)$ "to slip inside" suggests, more than possible alternative verbs like "to go inside" or "to enter" that no noise was made. So, the plaintiff chose systematically linguistic devices which lead to the conclusion that Mr. Van Gelder's breach of conduct is not so serious.

On the other hand, in the defendant's oral pleading, the checklist analysis reveals a coordinated and coherent series of choices in his formulations of the proposals for starting points for the discussion stressing the seriousness of Van Gelder's actions. An interesting, representative passage is the following:

(1) Van Gelder did not follow instructions from the team leaders on multiple occasions. He was untraceable twice with all the risks this entails. He brought himself in a position in which he could not be present at a training, due to excessive consumption of alcohol and nightly escapades. Time and again he gave contradictive explanations about his behaviours. Contrary to all agreements he drank alcohol, while he still was in competition and had a chance of winning a medal. Van Gelder has a bad influence on the team. His team members have taken offence of his confused and disorientated behaviour after his nightly adventures, and (...) his attitude of acting in defiance of the rules of the team (...).

In this passage, multiple relevant stylistic choices can be observed that can be found elsewhere in the defendant's pleading as well. First of all, a striking lexical choice (A1) is "nightly escapades": the word "escapade" suggests that Van Gelder's evening out was quite a bacchanal. In addition, the defendant talks about the incident by using nouns in the plural form (A1). He not only speaks about "nightly escapades", but also about "behaviours" and "adventures". "Instructions" were not followed on multiple "occasions", which lead to certain "risks". Further, according to the defendant, Van Gelder gave inconsistent "explanations", and drinking alcohol was against "agreements" and the "rules". This use of the plural form stresses the magnitude of Van Gelder's offence: it is suggested that he committed various offences and broke several rules. The seriousness of the incident is further stressed by the defendant's use of intensifiers (A5), i.e. words that stress the intensity of the message (cf. Burgers \& de Graaf 2013, p.171). For instance, the defendant states that drinking alcohol was against "all" agreements, contradictive 
explanations were given "time and again", there was "excessive" consumption of alcohol, and Van Gelder had not followed instructions on "multiple" occasions, indicating an attitude of acting "in defiance" of the rules. Moreover, the verb tenses (B6) in the fragment are striking: most of the sentences in the passage are formulated in the past tense. However, in the sentence "Van Gelder has a bad influence on the team" a switch is made to the present imperfective tense. By switching to the present imperfective, it is stressed that the incident had consequences that are still continuing. Finally, it is interesting that the defendant states that Van Gelder "could not be present at a training". The defendant could have said that Van Gelder "was not present at a training", but by using the modal auxiliary (B6) "could" here, it is stressed that Van Gelder was not able to be on time, which stresses the seriousness of the situation as well. So, the defendant's plea shows an opposite way of coloring the facts: in his elaboration of the events, he stresses the weightiness of the events, which lead to the conclusion that Van Gelder's removal from the Olympic team was justified.

The defendant's plea fragment in (1) shows another interesting word choice (A1/A4): the lawyer doesn't say that Van Gelder "got in a position" which made it impossible for him to join the training session, but he says that Van Gelder "brought himself" in this position. This way of choosing words implies Van Gelder's own responsibility for the events. The events did not just happen to him, he made them happen. This is also explicated by the use of active sentences (B9) in which Van Gelder is the agent: when the opening sentence of (2), for instance, would have been formulated by using a passive construction (i.e. "instructions were not followed (...)"), Van Gelder's responsibility for the actions leading to his dismissal from the Olympic team would have been less prominent.

The plea of the plaintiff, instead, contains many expressions which reduce Van Gelder's own hand in the events. He describes what happened in the Holland Heineken House as follows:

(2) Although he [i.e. Van Gelder] also ordered soft drinks, he was given a beer a few times (...). Apparently, there is no policy in Holland Heineken House to refrain from offering beer to athletes. At his guests' request (...), he accompanies them to their apartment.

What is striking about this fragment, is that Van Gelder is presented as an acting person (the agent) in acts which are not harmful for his reputation ("order soft drinks", "accompany guests"), while it is suggested that the reprehensible beers are pressed on him by a non-specified person: in the second and third sentence of (2), Van Gelder is, syntactically speaking, not presented as the agent but as the patient (B9). The strategy of presenting Van Gelder as a victim is also used by the plaintiff when he describes how the decision to send Van Gelder home, was taken and exe- 
cuted. The lawyer does not state that Van Gelder's coaches did not try to find out what had happened in "a talk" with him, but that they subjected him to "an interrogation" in which they did not inform him of what was at stake. He adds to this that Van Gelder is “immediately" taken to a plane. He doesn't just "leave the country", he "disappears", "as a thief in the night". He is actually being "abducted under escort", being "kicked out of the country". These intensifiers are of an hyperbolic nature and meant to give credibility to the idea that Van Gelder is not an offender, but mostly a victim.

Which linguistic choices did the judge make in formulating his proposals for starting points for the discussion? We said earlier that we may conjecture that the judge in his verdict will not downplay Van Gelders behaviour or blow it up, but that he will choose an argumentative strategy of being as neutral as possible with respect to Van Gelder's behaviour, restricting himself to facts that can be verified or objectified in the light of the applicable legal rules in this case without any personal appreciation. The linguistic choices in his order clearly reflect this strategy, as the following excerpts show:

(3) This summary proceeding primarily deals with the question whether the decision of NOC ${ }^{\star} \mathrm{NSF}$ [i.e. the Dutch Olympic Committee, TvH \& MvL] to exclude plaintiff of further participation to the Olympic Games is legitimate. NOC ${ }^{\star} \mathrm{NSF}$ has taken this decision on the basis of the agreement made between $\mathrm{NOC}^{\star} \mathrm{NSF}$ and plaintiff. This agreement states the rights and obligations of both parties in the preparation for and participation to the Olympic Games. (...) Art. 20 of the agreement furthermore states that if plaintiff does not abide with these obligations, $\mathrm{NOC}^{\star} \mathrm{NSF}$ is entitled to take measures as described in the article. This jurisdiction has been agreed upon with plaintiff. Plaintiff is therefore in principle obligated to agree with the measures imposed to him by NOC ${ }^{\star} \mathrm{NSF}$. The nature of these measures is in principle left to the jurisdiction of NOC ${ }^{\star} \mathrm{NSF}$. It is not incumbent upon the judge to decide if measures have to be taken, or which measures should be taken. The judge can only decide afterwards whether the measures taken by $\mathrm{NOC}^{\star} \mathrm{NSF}$ in the given circumstances were reasonable. The judge should apply considerable restraint in this matter. Only in case of unacceptability for the plaintiff of the decision by NOC ${ }^{\star} \mathrm{NSF}$ in terms of reasonability and fairness, is there a reason for the judge to intervene, as described for a binding party ruling in art XX paragraph 1 in connection with art XX of the Civil Code.

(4) With respect to the events having led to this measure, the following has been established on the basis of statements submitted in- and outside the court. Plaintiff has left the Olympic village on Saturday evening 6 August at 19:08, and came back on Sunday morning at 05:08. This is clear from his pass registration. It has been established that plaintiff subsequently went to the NOC and 
the Holland Heineken House. He texted this himself to his coach. The text messages show that the coach warned him not to drink, and to be home at 12:00 with the mention 'that he was still in the tournament and the contest'. This shows that the plaintiff was warned that everybody including NOC`NSF could see that he was in the Holland Heineken House. Finally, the coach warned the plaintiff that he was expected to train the following morning from 09:30 to 11:00. It has been established that the plaintiff did not appear at the training the next morning, that he was sleeping in his apartment and woke up at 15:00. Plaintiff did not answer the text message of his coach on Sunday morning 09:12 - shortly before the start of the training at 09:30 - asking him where he was. It has also been established - as admitted by claimant himself in court that he had drunk 4 or 5 beers in the Holland Heineken House. What else has happened that night, cannot be determined with precision.

One of the points of interests mentioned under category $A_{1}$ is whether the vocabulary is descriptive or evaluative. In the fragments (3) and (4) the word choice is clearly descriptive. For instance, whereas both plaintiff and defendant make use of intensifiers, these are absent in (3) and (4), leading to a more "factual" description of the events. In fragment (4), such an impression of factuality is also partly created by referring to very concrete times (e.g. "05:08", "09:12") (A2). In addition, in (4) the judge uses the factive verb ( $\left.\mathrm{A}_{4}\right)$ "establish" various times. By choosing the phrase "has been established", and by repeating this (repetition: $\mathrm{C}_{1}$ ), the factual nature of the embedded propositions in the sentence complements is stressed. ${ }^{12}$ Sentence complements (B6) are also linked to the matrix verb "to show" ("The text messages show that ..."; "This shows that..."). The subjects of these verbs refer to verifiable evidence supporting the description of the events that the judge is presenting; by leaving out a personal pronoun (D1) (cf. the possible alternative formulations "The text messages show to me..." / This shows to me..."), the suggestion is created that this evidence is indicative to anyone.

Personal pronouns are also absent in fragment (3): the judge refers to his own role by speaking of "the judge". This also has an objectifying effect: by choosing for "the judge" instead of "I" or "this court" (D1), the suggestion is created that any judge would act in the same way in similar circumstances. What is further striking in fragment (3) is the use of nonhuman agents in subject position whereby "this summary proceeding" and "this agreement" are personified $\left(\mathrm{C}_{3}\right)$ - the judge

12. This is also underlined by the last sentence in excerpt (4) "What else has happened that night, cannot be determined with precision." The formulation of this sentence implies that, in contrast, everything said before can be determined with precision, meaning that all other observations are irrelevant. Although this might be connected to the analysis, we refrain from doing so, since we used it here as a translation for the Dutch phrase "vast staat dat", which isn't a passive. 
seems not to be the agent himself in this procedure; he is only the instrument, the "mouth", of the procedure and of the agreement made between NOC*NSF and plaintiff. In addition, the judge uses the modal phrase "can only" (A4) to stress his limited role in this procedure.

In other words, fragments (3) and (4) show how linguistic devices used by the judge are instrumental in executing his argumentative strategy: stressing that he is neutral with respect to Van Gelder's behaviour, restricting himself to facts that can be verified or objectified and are relevant for a judgement from the perspective of the application of the relevant legal rules in this case and not from the perspective of his own personal appreciation, and foregrounding his limited discretion in this procedure.

All in all, the linguistic choices made by the plaintiff, the defendant and the judge clearly reflect their argumentative strategies. Formulated otherwise: our systematic linguistic-stylistic analysis reveals that their hypothesized respective argumentative strategies, and thus their strategic considerations, are systematically, coordinated and coherently realised in the argumentative discourse by their respective choices of the linguistic devices. In this way the systematic linguisticstylistic analysis contributes to the identification and analysis of the argumentative styles of the plaintiff, the defendant and the judge. ${ }^{13}$

\section{Conclusion}

In this paper we discussed and illustrated how a linguistic-stylistic analysis can be conducted systematically by making use of methodological insights from the so-called "linguistic-stylistic approach" (van Leeuwen 2015; Stukker \& Verhagen 2019; see also van Haaften \& van Leeuwen 2018; van Haaften 2019), and how such an analysis can be integrated with a pragma-dialectical analysis of argumentative discourse. Our aim was to show how such an integration could be helpful in analysing the presentational aspect of an argumentative style, and how the outcomes of such an analysis could be linked to another aspect of argumentative style, namely the strategic considerations implemented in the argumentative discourse. It is important to identify and analyse argumentative strategies because they contribute to the persuasive power of argumentative discourse and substan-

13. We think that our linguistic-stylistic analyses in this section also indicate that on a higher level of abstraction the argumentative styles of the plaintiff and the defendant could be characterized as "engaged " and that of the judge as "detached" (cf. van Eemeren 2019; this issue). This holds - we would conjecture - in most legal cases. For lack of space, we do not elaborate on this interesting issue here. 
tially determine the course taken by a discussion. And they are a constitutive element of the argumentative style of a specific argumentative discourse, instrumental to the implementation of an arguer's strategic scenario.

An important way of identifying argumentative strategies is the analysis of presentational devices, especially linguistic devices. Choices of discussion moves, audience-directed frames and presentational devices are all relevant dimensions in the selection of an argumentative strategy, but presentational devices in general and strategic linguistic choices in particular are the points of the realisation of the other dimensions in argumentative discourse and hence of their retrieval in analysis. It is necessary to apply a systematic method of linguistic-stylistic analysis for the identification and analysis of argumentative strategies. We have argued that for this purpose the method developed within the linguistic-stylistic approach is the best option.

The method that we have proposed for studying linguistic choices made in argumentative discourse systematically as an important means for identifying and analysing argumentative strategies, consists of 4 steps (see the end of Section 3 ). Step 1 consists of making an argumentative reconstruction of the discourse by using the analytical tools from pragma-dialectics, whereas Step 2 consists of a systematic bottom-up analysis of linguistic choices, leading to a long list of linguisticstylistic observations. In step 3, this list is reduced by connecting the findings from Step 2 to the outcomes of the argumentative reconstruction in Step 1. This means that for each linguistic-stylistic device it is investigated (on the basis of a semantic and pragmatic analysis of the language forms) whether, and precisely how, they contribute to achieving the argumentative goals that the arguers allegedly have. The alleged argumentative goals are motivated by the "analytic overview" of the discourse in which a.o. the dialectical and rhetorical goals of the empirical counterparts of the discussion stage(s) in the speech event(s) have been determined, taking into account the restrictions and opportunities imposed by the activity type. In Step 4, finally, the analyst tries to find (on the basis of Steps 3 and 1), clusters of linguistic choices that "point" into the same direction and that can be connected to the dialectical and rhetorical goals of the arguers. It should be stressed that Steps 1-3 not necessarily have to be conducted in this order: in practice, they could also be turned around and will often be carried out in a cyclic, hermeneutic process of analysis (cf. Stukker \& Verhagen 2019, pp. 59-88).

As we have argued, an important methodical instrument in Step 2 of the analytical procedure proposed here is the use of a linguistic checklist. The added value of the checklist lies in its heuristic function: it more or less "forces" the analyst to take into consideration a wide variation of linguistic devices and as such, reduces the chance that pertinent linguistic choices are missed (cf. Van Leeuwen 2014:237-238). In the Yuri case, for instance, we probably would have overlooked 
the plaintiff's strategic use of verb tenses and modal auxiliaries: these subtle, more or less "hidden" grammatical presentational devices would probably not have come to light when the analysis had been carried out without using a checklist. In this way the checklist can also be of help in identifying more precisely not only individual strategic manoeuvres, but in particular argumentative strategies.

Nevertheless, as we noted earlier, the linguistic-stylistic method is not a magic formula. Going systematically through the checklist, for example, reduces the risk of overlooking pertinent stylistic devices, and their systematic relation with other devices, but it cannot eliminate this risk completely (see Section 3). In addition, behind every category mentioned in the checklist, there hides a whole "world" of linguistics. This may hamper the linguistic-stylistic analysis, because the categories mentioned in the checklist are often not directly applicable to the analysis of specific discourses. For instance, category A1 in the checklist proposed by Leech and Short (2007) steers the analyst among other things to a search for "particular suffixes". This helped us to identify the defendant's strategic use of plural forms ("escapades", "behaviours", "adventures", etc.). This "translation" from an abstract category like "suffixes" to a concrete linguistic-stylistic phenomenon "plurals" is something that the analyst needs to do himself - based on linguistic knowledge. However, this is a typical characteristic of linguistic-stylistic research as such: without the use of a checklist, this would also be the case (cf. van Leeuwen 2014:238).

All in all, the analytical method we propose for identifying and analysing argumentative strategies, integrates insights from pragma-dialects and linguisticstylistics. Although it does not provide a panacea for identifying and analysing argumentative strategies and does not reduce this to a relatively uncomplicated activity, we hope to have shown that this method can provide a valuable contribution to identifying and analysing argumentative strategies in a systematic way and in doing so contributes to the identification and analysis of (other aspects of) argumentative styles.

\section{References}

Burgers, C. \& de Graaf, A. (2013). Language intensity as a sensationalistic news feature: the influence of style on sensationalism perceptions and effects. Communications 38: 167-188. https://doi.org/10.1515/commun-2013-0010

Fahnestock, J. (2009). Quid pro nobis. Rhetorical stylistics for argument analysis. In Examining Argumentation in Context. Fifteen Studies on Strategic Maneuvering, ed. F.H. van Eemeren (pp. 191-220). Amsterdam [etc.]: John Benjamins. https://doi.org/10.1075/aic.1.12fah 
Fahnestock, J. \& Y. Tonnard. (2011). Amplification in strategic maneuvering. In Keeping in touch with Pragma-Dialectics, eds. E. Feteris, B. Garssen and F. Snoeck Henkemans (pp. 103-116). Amsterdam [etc.]: John Benjamins. https://doi.org/10.1075/z.163.08fah

Langacker, R.W. (1990). Concept, image and symbol: The cognitive basis of grammar. Berlin: Mouton de Gruyter. https://doi.org/10.1515/9783110857733

Leech, G. \& Short, M. (2007). Style in fiction. A linguistic introduction to English fictional prose. Second edition. Harlow: Pearson Longman.

van Eemeren, F. H. (2010). Strategic maneuvering in argumentative discourse. Amsterdam [etc.]: John Benjamins. https://doi.org/10.1075/aic.2

van Eemeren, F.H. (2018). Argumentation theory: A pragma-dialectical perspective. Cham: Springer. https://doi.org/10.1007/978-3-319-95381-6

van Eemeren, F.H. (2019). Argumentative style: a complex notion. Argumentation 33: 153-171. https://doi.org/10.1007/s10503-019-09478-y

van Eemeren, F.H. This issue. Examining Argumentative Style: A New Theoretical Perspective. Journal of Argumentation in Context.

van Eemeren, F.H. \& Houtlosser, P. (1999). Strategic manoeuvring in argumentative discourse. Discourse Studies 1: 479-497. https://doi.org/10.1177/1461445699001004005

van Eemeren, F. H. \& Snoeck Henkemans, A. F. (2016). Argumentation: Analysis and evaluation (2nd rev. ed.) New York/London: Routledge. https://doi.org/10.4324/9781315401140

van Haaften, T. (2019). Argumentative strategies and stylistic devices. Informal Logic, 39, 301-328. https://doi.org/10.22329/il.v39i4.6037

van Haaften, T. \& van Leeuwen, M. (2018). Strategic Maneuvering with Presentational Devices: A Systematic Approach. In Argumentation and Inference. Proceedings of the and European Conference on Argumentation, Fribourg 2017, Volume II. Studies in Logic 76, eds. S. Oswald \& D. Maillat (pp. 873-886). London: College Publications.

van Leeuwen, M. (2014). Systematic stylistic analysis. The use of a checklist. In From Text to Political Positions. Text analysis across disciplines, eds. B. Kaal, I. Maks \&

A. van Elfrinkhof (pp. 225-244). Amsterdam [etc.]: John Benjamins. https://doi.org/10.1075/dapsac.55.11lee

van Leeuwen, M. (2015). Stijl en politiek. Een taalkundig-stilistische benadering van Nederlandse parlementaire toespraken. [Style and politics. A linguistic-stylistic approach to Dutch parliamentary speeches] Dissertation Leiden University. Utrecht: LOT. Stukker, N. \& A. Verhagen. (2019). Stijl, taal en tekst: stilistiek op taalkundige basis. [Style, language and text: stylistics on a linguistic foundation.] Leiden: Leiden University Press.

\section{Appendix. A checklist of linguistic and stylistic categories (Leech and Short 2007)}

\section{A. Lexical categories}

1. GENERAL. Is the vocabulary simple or complex? Formal or colloquial? Descriptive or evaluative? General or specific? How far does the writer make use of the emotive and other associations of words, as opposed to their referential meaning? Does the text contain idiomatic phrases or notable collocations, and if so, with what kind of dialect or register are these 
idioms or collocations associated? Is there any use of rare or specialized vocabulary? Are any particular morphological categories noteworthy (e.g. compound words, words with particular suffixes)? To what semantic fields do words belong?

2. NOUNS. Are the nouns abstract or concrete? What kinds of abstract nouns occur (e.g. nouns referring to events, perceptions, processes, moral qualities, social qualities)? What use is made of proper names? Collective nouns?

3. ADjeCtives. Are the adjectives frequent? To what kinds of attribute do adjectives refer? Physical? Psychological? Visual? Auditory? Colour? Referential? Emotive? Evaluative? etc. Are adjectives restrictive or non-restrictive? Gradable or non-gradable? Attributive or predicative?

4. VERBs. Do the verbs carry an important part of the meaning? Are they stative (referring to states) or dynamic (referring to actions, events, etc.)? Do they 'refer' to movements, physical acts, speech acts, psychological states or activities, perceptions, etc.? Are they transitive, intransitive, linking (intensive), etc.? Are they factive or non-factive?

5. ADVERBs. Are adverbs frequent? What semantic functions do they perform (manner, place, direction, time, degree, etc.)? Is there any significant use of sentence adverbs (conjuncts such as so, therefore, however; disjuncts such as certainly, obviously, frankly)?

\section{B. Grammatical categories}

1. SEntence types. Does the author use only statements (declarative sentences), or do questions, commands, exclamations or minor sentence types (such as sentences with no verb) also occur in the text? If these other types appear, what is their function?

2. SENTENCE COMPLEXity. Do sentences on the whole have a simple or complex structure? What is the average sentence length (in number of words)? What is the ratio of dependent to independent clauses? Does complexity vary strikingly from one sentence to another? Is complexity mainly due to (i) coordination, (ii) subordination, or (iii) parataxis (juxtaposition of clauses or other equivalent structures)? In what parts of a sentence does complexity tend to occur? For instance, is there any notable occurrence of anticipatory structure (e.g. of complex subjects preceding the verbs, of dependent clauses preceding the subject of a main clause)?

3. ClAUSE TYPES. What types of dependent clause are favored: relative clauses, adverbial clauses, different types of nominal clauses (that-clauses, wh-clauses, etc.)? Are reduced or non-finite clauses commonly used and, if so, of what type are they (infinitive clauses, -ing clauses, -ed clauses, verbless clauses)?

4. ClAUSE STRUCtURE. Is there anything significant about clause elements (e.g. frequency of objects, complements, adverbials; of transitive or intransitive verb constructions)? Are there any unusual orderings (initial adverbials, fronting of object of complement, etc.)? Do special kinds of clause construction occur (such as those with preparatory it or there)?

5. NOUN PHRASES. Are they relatively simple or complex? Where does the complexity lie (in premodification by adjectives, nouns, etc., or in postmodification by prepositional phrases, relative clauses, etc.)? Note occurrence of listings (e.g. sequences of adjectives), coordination or apposition.

6. VERB PHRASES. Are there any significant departures from the use of the simple past tense? For example, notice occurrences and functions of the present tense; of the progressive aspect (e.g. was lying); of the perfective aspect (e.g. has/had appeared); of modal auxiliaries (e.g. can, must, would, etc.) Look out for phrasal verbs and how they are used. 
7. OTHER PHRASE TYPES. Is there anything to be said about other phrase types: prepositional phrases, adverb phrases, adjective phrases?

8. WORD CLASSES. Having already considered major or lexical word classes, we may here consider minor word classes ('function words'): prepositions, conjunctions, pronouns, determiners, auxiliaries, interjections. Are particular words of these types used for particular effect (e.g. the definite or indefinite article; first person pronouns $I$, we, etc.; demonstratives such as this and that; negative words such as not, nothing, no)?

9. GENERAL. Note here whether any general types of grammatical construction are used to special effect; e.g. comparative or superlative constructions; coordinative or listing constructions; parenthetical constructions; appended or interpolated structures such as occur in casual speech. Do lists and coordinations (e.g. lists of nouns) tend to occur with two, three or more than three members? Do the coordinations, unlike the standard construction with one conjunction (sun, moon and stars), tend to omit conjunctions (sun, moon, stars) or have more than one conjunction (sun and moon and stars)?

\section{Figures of speech, etc}

Here we consider the incidence of features which are foregrounded by virtue of departing in some way from general norms of communication by means of the language code; for example, exploitation code. For identifying such features, the traditional figures of speech (schemes and tropes) are often useful categories.

1. GRAmmatical AND Lexical. Are there any cases of formal and structural repetition (anaphora, parallelism, etc.) or of mirror-image patterns (chiasmus)? Is the rhetorical effect of these one of antithesis, reinforcement, climax, anticlimax, etc.?

2. PHONOLOGiCAl schemes. Are there any phonological patterns of thyme, alliteration, assonance, etc.? Are there any salient rhythmical patterns? Do vowel and consonant sounds pattern or cluster in particular ways? How do these phonological features interact with meaning?

3. TROPES. Are there any obvious violations of, or departures from, the linguistic code? For example, are there any neologisms (such as Americanly)? Deviant lexical collocations (such as portentous infants)? Semantic, syntactic, phonological, or graphological deviations? Such deviations (although they can occur in everyday speech and writing) will often be the clue to special interpretations associated with traditional poetic figures of speech such as metaphor, metonymy, synecdoche, paradox and irony. If such tropes occur, what kind of special interpretation is involved (e.g. metaphors can be classified as personifying animising, concretising, synaesthetic, etc.)? Because of its close connection with metaphor, simile may also be considered here. Does the text contain any similes, or similar constructions (e.g. 'as if' constructions)? What dissimilar semantic fields are related through simile?

\section{Context and cohesion}

- COHEsion: ways in which one part of a text is linked to another (the internal organisation of the text).

- CONTEXT: the external relations of a text or a part of a text, seeing it as a discourse presupposing a social relation between its participants (author and reader; character and character, etc.), and a sharing by participants of knowledge and assumptions. 
1. COHEsion. Does the text contain logical or other links between sentences (e.g. coordinating conjunctions, or linking adverbials)? Or does it tend to rely on implicit connections of meaning? What sort of use is made of cross-reference by pronouns (she, it, they, etc.)? By substitute forms (do, so, etc.), or ellipsis? Alternatively, is any use made of elegant variation - the avoidance of repetition by the substitution of a descriptive phrase (as, for example, 'the old lawyer' or 'her uncle' may substitute for the repetition of an earlier 'Mr Jones')? Are meaning connections reinforced by repetition of words and phrases, or by repeatedly using words from the same semantic field?

2. CONTEXT. Does the writer address the reader directly, or through the words or thoughts of some fictional character? What linguistic clues (e.g. first person pronouns I, me, my, mine) are there of the addresser-addressee subject? If a character's words or thoughts are represented, is this done by direct quotation (direct speech), or by some other method (e.g. indirect speech)? Are there significant changes of style according to who is supposedly speaking or thinking the words on the page?

\section{Address for correspondence}

Ton van Haaften

Leiden University Centre of Linguistics (LUCL)

Faculty of Humanities

Leiden University

P.O. Box 9515

2300 RA Leiden

The Netherlands

t.van.haaften@hum.leidenuniv.nl

\section{Co-author information}

Maarten van Leeuwen

Leiden University Centre of Linguistics (LUCL)

Faculty of Humanities

Leiden University

m.van.leeuwen@hum.leidenuniv.nl 